\title{
Development and Validation of Work Environment Services Scale (WESS)
}

\author{
Harold Andrew Patrick' ${ }^{1}$ Jacqueline Kareem²
}

Submitted: 25.03.2020. Accepted: 26.03.2021

\section{Abstract}

Purpose: This study presents a nine-factor, 32-item measure of work environment scale in the service sector. A healthy work environment is one in which employees trust the people they work for, have pride in what they do, and enjoy working with the people (Levering and Moskowitz, 2004).

Methodology: This instrument builds on the conceptual model espoused by Insel and Moos (1974), Gordon (1973), Fletcher and Nusbaum (2010), Amabile et al. (1996), and Spector (2003). The scale included items elicited through a literature review, the use of the Delphi technique with a panel of experts, and tested on 824 full-time employees from nine service sector industries and five major cities in India.

Findings: The Work Environment Services Scale (WESS) is a reliable and valid scale useful for measuring the nine work environment factors in the Indian services organization, with its own norms and a detailed manual.

Originality/Value: The prevailing scales for measuring work environment do not capture the influence of ethics, recreation facilities, and the impact of social giving on the work environment. Most scales were suitable for sectors in the Western context, and there were no Indian scales measuring service employees' perception of their work environment.

Keywords: work environment, service sector, employee motivation, scale development, organizational behavior.

\section{JEL: C38}

CMS Business School, Jain University, No.17, Seshadri Rd, Gandhi Nagar, Bengaluru, Karnataka 560009, India, e-mail: harold.patrick @jainuniversity.ac.in.

2 Corresponding author, School of Education, Christ University, Hosur Road, Bengaluru - 560029, Karnataka, India; jacqueline.Ioleta@ christuniversity.in; https://orcid.org/0000-0002-1759-5827. 


\section{Introduction}

Work Environment plays a pivotal role in today's competitive workplace. The work environment is proven to have a major impact on an individual's work behaviors, stress, and performance. A healthy Work Environment is one in which employees trust the people they work for, have pride in what they do, and enjoy working with the people they work with (Levering and Moskowitz, 2004).

Organizations' processes influence newcomers by creating experiences or environments that transmit beliefs, values, and norms (VanMannen and Schein, 1979). Shelly, Gilson, and Blum (2000) find that higher job satisfaction and lower intentions to leave appear in individuals whose work environments complement the creative requirements of their jobs. Work environment attributes known to play a key role in a satisfied workforce include relationship with peers, supervisors, and subordinates, task autonomy, role clarity, organizational control mechanisms, and physical infrastructure.

This article details the concept of work environment, the rational for tool development and the measurement of work environment by researchers worldwide. Based on the gaps identified and the suitability within the Indian context the researchers developed a scale for the Indian services sector ensuring to adher to the robustness of the scale development process. The article details the item generation process, the identification of factors and its definitions, scoring and norms for interpretation. The contents of this article can be used by researchers as a manuel for the scale to validate.

\section{The Concept of Work Environment}

Work environment, in the literal sense, would mean your surroundings at the place of occupation, e.g. inside, outside, at a desk, or in a cubicle. The term has also come to mean a mental state while on the job, which may be positive, negative, friendly, and so on. Work environment plays a pivotal role in today's competitive workplace. A competitive work environment may influence individuals' attitudes, behaviors, stress, and performance. A positive work environment makes employees feel good about coming to work, which provides the motivation that sustains them throughout the day. Although the term work environment has not been operationally defined in the literature, they are defined as e.g. healthy work environment, positive workplace, or competitive workplace.

Looking into theoretical concepts in the workplace that determines company culture, Newton (2016) has described company culture to not only range from how employees 
work, dress, or act, but it also refers to any other concept that affects the environment in a workplace. Newton speaks about behavior, work styles, dress, and appearance, workplace atmosphere, and communication.

Work environment is known to be relatively more important to the success of organizations involved in the service sector. This is primarily because most employees in the service sector directly contribute to the revenues of the organization by engaging directly in customer-serving roles. Thus, the core values and strengths of the organization are championed by these employees.

Evidence gleaned from past studies strongly supports the notion that the environment exerts considerable influence on human behavior. Moreover, it constitutes a major determinant of effective functioning and satisfaction among people in the environment. Studies show that work environment affects organizational success (May, Lau, and Johnson, 1999; Ballou, Godwin, and Shortridge, 2003; Patterson, Warr, and West, 2004). Further evidence shows that the companies that are best employers are more productive than similar companies that do not have such a work environment (Ballou, Godwin, and Shortridge, 2003; Levering and Moskowitz, 2005, Levering and Moskowitz, 2006). Companies in which employees have a higher perception of the work environment have a higher market value (Ballou, Godwin, and Shortridge, 2003).

Work environment can be described as the "location where a task is completed." Scott, Jusanne, and Steven (2000) report that working conditions are linked to employees' job involvement and satisfaction. Work environment must be conducive to routine, innovative, and challenging work. After all, work environment is made up of many factors. Some of the basic and common factors that constitute the work environment are pay, work hours, rest periods, paid holidays and vacations, safety and security, uniform, and possibilities of advancement. These working conditions in an organization should be able to bring out the employee's best efforts and output. The work environment should make employees feel comfortable and safe while working. They should be encouraged and motivated to do their work with pleasure. The work of the organization that the employee does can have the intensity and ease with which they do their personal work. Along with work, the work environment must support the employees by allowing them to rest and relax on weekends (National Portal of India, n.d.).

A healthy work environment is one that is safe, empowering, and satisfying. Parallel to the World Health Organization's definition of health, a healthy work environment is not merely the absence of real and perceived threats to health but a place of "physical, mental, and social well-being" that supports optimal health and safety. Two main 
elements of the definition - physical and psychosocial - seem to dominate perceptions about the workplace among employees. In his study to examine the effect of these two dimensions of employee perception on job satisfaction and performance, Srivastava (2008) reveals that among the various components of work environment, working conditions, welfare provisions, interpersonal relations, it is trust and support that predominantly contribute to employees' job behavior and organizational effectiveness. The results also specify that the psychosocial environment in a workplace exerts more impact on employees' job behavior and organizational effectiveness than does the physical environment.

\section{Rationale for Tool Development}

India now has expertise and skills across a vast and wide-ranging spectrum of service sectors, such as healthcare, tourism, education, engineering, communications, transportation, information technology, banking, finance, and management. A sizeable part of this workforce of professionals forms India's growing consultancy sector, which is offering its accumulated experience and expertise at home and abroad. India is now home to globally recognized companies in pharmaceuticals, steel, information, and space technologies industries, and it is a growing voice on the international stage that better suits the country's enormous size and potential. India is unleashing a host of new opportunities to forge a twenty-first-century nation, which is linked to the largest and youngest workforce the world has ever seen. How India develops its significant human potential and lays down new models for the growth of its burgeoning towns will largely determine the shape of the future for the country and its people in the years to come (The World Bank, 2014). Hence, the present study focuses on the Indian service sector. Employees in the service sector play a crucial role in sustaining the market, and they are the most important assets of an organization. Employee attitude and behavior play a vital role in the quality of service.

The perception of employees toward the environment in the workplace is an area of theoretical and empirical concern. Biswas and Varma (2007) suggest that Indian organizations must pay attention to employee perceptions of the work environment and that human resource strategies should go beyond establishing policies and procedures to fostering an employee-friendly work environment that promotes both in-role and extra-role performance. Kaliath and Kaliath (2012) provide insights into six specific work-environmental issues influencing employee wellbeing, including workplace bullying, interorganizational networks, professional contractor well-being, intergenerational differences, commitment and intention to leave, and workengagement. Table 1 
summarizes some popular scales developed by researchers who measure work environment with the various dimensions and in different western contexts.

\section{Table 1. List of scales and their dimensions measuring work environment}

$1 \quad$ Insel and Moos (1974)

2 Gordon (1973)

3

Fletcher and Nusbaum
(2010)

4 Chan (2001)

5 Roche et al. (2009)

$6 \quad$ Amabile et al. (1996)

Karasek and Theorell (1990)

8 Spector and Fox (2003)

\section{Interpersonal dimension, Personal growth dimension} System Maintenance and System change

Self-subordination (willingness submission to authority); Impersonalization (preference for impersonal relationships with others on the job); Role conformity (strict adherence to rules and regulations); and Traditionalism (strong organizational identification)

Competition for tangible rewards,

No tangible rewards, recognition, status and competition influenced by co-workers

Individualization, Innovation, Involvement, Personalization

Opportunity, Information, Support, Resources, Formal power, Informal power

Encouragement of creativity, Autonomy or freedom, Resources, Pressures, Organizational impediments to creativity

Skill discretion, Decision authority, Job security, Coworker support, Supervisory support, Overall control, Overall work support, Overall resources

This scale focuses on the autonomy for the employees. The authors suggest that it is feasible to develop fact-based items for scales of work environment that reduce the subjectivity of the responses

Source: own elaboration.

Although researchers indicate that the scales were established on conceptual ground, the prevailing scales for measuring work environment do not capture the influence of ethics, recreation facilities, and the impact of social giving on the work environment - i.e. social responsibility - which is pertinent for the modern Indian work environment. Most of the scales were suitable for sectors in the Western context, and there were no Indian scales measuring service employees' perception of their work environment.

Insel and Moos (1974) propose three forms for the work environment scale: the Real Form (Form R), which measures perceptions of existing work environments; the Ideal Form (Form I) which measures conceptions of ideal work environments; and the Expectations Form (Form E), which measures expectations about work settings. The scholars 
measure work environment based on the following dimensions, relevant across all work environments. Peer cohesion, Involvement, and Supervising manager support. The personal growth dimension has subscales which are Autonomy, Task orientation, and Work pressure. System Maintenance and System change also have dimensions and subscales, which are Clarity, Control, Innovation, and Physical Comfort.

Gordon's (1973) Work Environment Preference Schedule (WEPS) was designed to assess the work environment. These fall into four separate categories: a) Self subordination (willingness submission to authority); b) Impersonalization (preference for impersonal relationships with others on the job); c) Role conformity (strict adherence to rules and regulations); and d) Traditionalism (strong organizational identification).

According to Chan (2001), the Clinical Environment Inventory (CLEI) is distributed in five subscales such as Individualization, which refers to autonomy, innovation, involvement, and personalization. The CLEI refers to the relationship dimension (Chan, 2001b), which is one of the three human environment categories that identifies the nature and intensity of personal relationships within the environment and task orientation.

Roche et al. (2010) measure the work environment by the Conditions for Work Effectiveness Questionnaire-II (CWEQ-II) to find sources of power - also known as structural empowerment - described by opportunity, information, support, resources, formal power, and informal power. The study finds that the practice environment contributes directly to nursing job satisfaction.

Amabile et al. (1996) describe the development and validation of a new instrument called KEYS: the study assesses the work environment for creativity. They consider that perceptions of a work environment are measured by the following dimensions: a) encouragement; b) creativity; c) autonomy or freedom; d) resources; e) pressures; f) organizational impediments to creativity. The scale distinguishes between high-creativity projects and low-creativity projects.

The study by Spector and Fox (2003) develops a factual autonomy scale to reduce subjectivity in the assessment of job environment. This scale focuses on the autonomy of employees and suggests that it is feasible to develop fact-based items for scales of work environment that reduce the subjectivity of responses.

For Karasek and Theorell (1990), workplace scale has the following dimensions: skill discretion, decision authority, job security, co-worker support, supervisory support, overall control, overall work support, and overall resources. 


\section{Literature Review}

Studies in the Healthcare Service Sector. This study has reviewed research studies conducted in various service sectors. Islam et al. (2020) show the moderating role of work environment on green resource management practices and turnover intentions among employees in the tourism sector. They report that there is no moderating effect of work environment on resource management practices and turnover intentions, but a few green resource management practices do have a direct impact on turnover intention. Looking at the impact of psychosocial work environment on recipient satisfaction, others find that the psychosocial work environment of nursing assistants and their satisfaction in their work can be increased by good leadership (Lundgren et al., 2019). A study among rural hospitals nurses on the association of work environment evidences that work environment is significantly associated with adverse events (Smith et al., 2019). Cooley, Pedersen, and Mainsbridge (2014) provide a better outcome in the workplace by implementing non-purposeful physical activity "e-health intervention" in a professional workplace. They asked health professionals to evaluate the full measure of such an intervention: 15 interviews resulted in a range of subjective outcomes. The participants not only experienced positive but also negative outcomes due to workflow disruption and change of work habits. The results of the study conclude that subjective evaluation can be used to identify the factors that influence judgment on the efficacy of workplace health interventions. Marquez (2007) suggests that organizations should involve relevant stakeholders to develop a positive, trusting, and open process safety culture in each US refinery. For most organizations, HR executives should focus on making sure that corporate safety culture exists. Weinstock (1994) argues that creating positive attitudes and behaviors concerning safety is crucial to creating a company culture that values and practices safety, and many safety managers find incentive programs a valuable part of safety programs. For managers trying to create a total safety culture, awards offer a way to keep safety on employees' minds and reward safe behavior.

Studies in the Education Service Sector. Sonmark and Modin (2017) study psychosocial work environment and health complaints in schools to find that psychosocial work environment predicts students' health complaints and that social support is a stress moderating factor, which is a part of work environment. Ongori (2007) shows that work environment and burnout are highly interactive with work environment variables of supervisor support and clarity, which are identified as key factors in burnout. Mayhew, Grunwald, and Dey (2006) argue that achieving a positive campus climate for diversity from the staff perspective requires factors that create a positive climate for diversity, and they demonstrate how these factors predict outcomes related to achieving a positive campus climate for diversity. Based on survey data collected from 
437 staff members employed at a large, public, and predominantly white university in the Midwest, their results suggest that the institution's ability to achieve a positive climate for diversity reflects not only the personal characteristics of the staff member (race, gender, education level, and age) but also their perceptions of the immediate work environment.

Studies in the Management Sector. A study conducted among the hotel industry employees reports that there is a causal relationship between supportive work environment and employee retention, and it emphasizes the importance of imparting a supportive work environment to foster healthy relationships among all stakeholders (Naz et al., 2020). A study on the mediating role of work environment on the relationship between workplace violence and employee engagement - with the sample of employees from various service sectors like customer care, managerial, or IT professionals in Pakistan - the findings show that work environment has a significant negative effect on employee engagement and mediates between the relationship of workplace violence and employee engagement. This study underlines the necessity of having a supportive work environment (Saleem, Shenbei, and Hanif, 2020). A study about the role of work environment in the job satisfaction of US federal employees evidences that their job, work groups, and work environment have significant effects on job satisfaction, which implies the importance of a supportive work environment (Wang and Brower, 2019). Ming (2019) indicates that customary HR practices have fallen behind the requirements of their organizations and society in general, they have realized that elements like resilience, development attitude, and viewpoint taking are the main experiences into a worker's effect, the very meta-learning characteristics that we know are prescient of labor force accomplishment at individual and group levels are by and large what these neuro-technologies are changing. Thus, Ming emphasizes the transformation of HR practices, calling for a change in the work environment of companies. Data analysis on psychosocial risk management and psychosocial work environment from Denmark employees implies that Danish work environments with a high exertion in psychosocial hazard the executives in the former year had a little however altogether more sure appraising of the psychosocial workplace by the representatives (Thorsen et al., 2017). This study covers 7565 employees from various service sectors in Denmark. The study foregrounds the importance of psychosocial work environment in workplaces. Looking into the work environment in the handicraft industry, Dhingra reports that physical working conditions, ergonomics, safety, and working hours all contribute to a conducive work environment (Dingra et al., 2017). Fabre (2005) argues that a staff-friendly culture includes respect, simplicity, flexibility, integrity, culture, and communication, and she shows how to apply those building blocks to recruitment, retention, teamwork, safety, diversity, leadership, and problem-solving strategies. Aurelio (1996) emphasizes the 
basic tools such as trust, support, staff empowerment, and positive work environment. He says that while we cannot promise our staffers a lifelong job, we can create a corporate culture in which the support staff can grow their skills and abilities. Motivating people requires analysis and the timely tracking of results. Similarly, Segall (1991) writes that supervisors can influence the climate or atmosphere in which their employees work. To a large extent, the climate of the workplace is determined by supervisors' leadership styles and their assumptions about their employees and why they work. Such a climate can be autocratic, democratic, or permissive. Segall also explains that supervisors create the working climate, while the best climate is the one that enables the highest level of productivity; and climates will change according to the needs of the people in that environment. How you behave influences those who work for you more than what you say. Even the best climate requires maintenance. This means listening to new ideas, reinforcing positive behavior, and redirecting other behavior. The ideal working climate creates a feeling of excitement among employees - it inspires them to do a better job.

The literature analysis emphasizes that if the practice of culture in organizations is positive, it will demonstrate cooperation, align with practice goals, support goals accomplishment, encourage new ideas and creativity, foster trust among employees, quicken response to needed change, bring out workers' best performance, and give decision-making authority to employees at all levels. Moreover, it will energize employees to excel in their jobs and support them to meet their personal needs and goals. Five principles that can help managers create a great corporate culture are the following: 1. determine where your organization is on the trust continuum; 2. managers must understand that every interaction is an opportunity to build trust and that missteps can quickly break trust; 3 . focus on a few key trust-building changes and pursue these consistently and relentlessly; 4 . understand that how you actually conduct change to improve the work environment is more important than what this change is; 5 . leverage what is already special by encouraging employees to communicate and celebrate the unique strengths of company culture that energize them to contribute their best. This powerful combination of trust, pride, and camaraderie inspires employees to be creative and innovative, which has a powerful impact on performance.

There is evidence that competitive salaries and benefits, staff development, awards and recognition, management training, and leadership involvement are the ways to increase a positive work environment in the healthcare industry. A positive environment helps to attract and retain good employees. When competitive salaries and benefits do not suffice to attract scarce IT workers, some companies are prepared to create a positive work environment in any way they can. As a result, new facilities are expected 
to provide IT departments with more space and more opportunity to quickly boost their programming staff.

Prevailing work measurement scales do not consider the influence of ethics as a dimension in the work environment. The influence of good facilities like cafeterias, children day-care centers, flexible work options, or safety measures like training on the emergency response has not been factored as a dimension in the work environment. In turn, our scale intends to include recreation facilities, events, and ethical practices.

Building on several different studies, our work environment manual measures employee perception of their workplace.

\section{Methodology}

\section{Tool Development}

The initial pool of items for the work environment manual was developed after reviewing the existing scales measuring work environment. The choice and phrasing of statements echoed the formulation of constructs that measure the perception of work environment. The dimensions of autonomy, teamwork, managerial support, peer togetherness, task orientation, role clarity, innovation, and work stress are the constructs on which we based the items. Initially, 112 items were mostly generated from the scales listed in Table 1. Most selected items were modified to address the gaps in the present scales to suit the Indian work ethos. These items were circulated among 25 experts (academic and industry) for qualitative validation.

Table 2. Work environment services scale: initial set of items

\section{STATEMENT to be read with the preface In My Organization...}

1 Employees willingly help a new entrant feel comfortable.

2 Employees take a personal interest in colleagues work related issues (positive sense).

3 Employees rarely socialize (spend time) with other co-workers.

4 Employees often talk to each other about their personal problems. 
5 Employees speak negatively about colleagues.

6 There is little team togetherness and unity.

Employees willingly take time off their busy schedule to help colleagues deal with work-related issues.

8 Employees feel proud to be a part of this organization.

9 Employees generally work very hard even though it is routine work.

10 It is difficult to get employees to work here.

11 Employees share the same values and beliefs of the organization.

12 Employees put quiet a lot of effort only during deadlines.

13 Employees work harder than what is actually required.

14 Employees speak highly of their job to outsiders.

15 I enjoy being part of this organization because of the work I'm involved in.

16 My immediate manager supports me when things go wrong.

17 My manager recognizes and gives credit for the efforts I put in.

18 Too much is expected of employees within a short time frame.

19 My manager always closely supervises every aspect of my job.

20 My immediate manager is sensitive to work/life issues.

21 My manager aids me in planning systematically for my career growth.

22 Employees are free to discuss their personal problems with their managers.

23 My manager gives me opportunities for learning and development.

24 My manager finds fault over petty issues.

25 I have a feeling of being valued in the eyes of senior management.

26 There is a great deal of freedom to execute my work.

27 Employees take initiative to do things here.

28 Managers generally do not interfere with the decisions of the employees concerned with their work.

29 Employees can function independent of supervisors (positive sense).

30 Good suggestions from employees tend to get ignored here for no reason.

31 Responsibility for every task is decentralized in this organization.

32 Employees can alter the process of work with management approval.

33 There is nothing called "putting it off till the next day" in this organization. 
34 Getting things done by employees generally involves the supervisor being aggressive.

35 There's a lot of time wasted because of inefficiencies.

36 There is no bias in terms of delegating responsibility to the employees.

37

Achievement of goals and how to achieve them are both equally emphasized.

38 My organization believes in "task first," "relationship next" philosophy.

39 There is too much mental stress because of the work involved.

40 There is always a constant pressure on the employees to keep working.

41 There are too many aggressive deadlines to be met.

42 There is no time for relaxation or free talk in the organization.

43 Grievance handling mechanism is effective in this organization.

44 There is an utter imbalance between personal life and work life because of work pressure.

45 Employees are not clear of what is expected of them.

46 Rules and regulations are ambiguous and keep changing very often.

47 There is always a discrepancy between job description and expectations from supervisors.

48 Pay policies, incentives, and benefits are not transparent.

49 The responsibilities of each employee are clearly defined.

50 Employees are rarely confused what they need to do here.

51 The organization emphasizes strict adherence to rules and regulations.

52 Employees generally follow predefined rules in task implementation.

53 There is no restriction on dress code while on the job.

54 When employees come in late, they have to compensate by staying late.

Nobody is an exception to the rules and regulations set by the organization.

56 Employees are encouraged to propose different new ideas.

57 This organization encourages novel ideas.

58 New approaches are generally discouraged.

59 Management wants to avoid risk in trying out new ideas.

60 Employees are valued for innovations and doing things differently.

61 The organization invests a lot of resources on innovation and research. 
62 Workplace ambiance communicates a sense of warmth to the employees.

63 There is good ventilation in the workplace.

The infrastructure/physical layout in the organization motivates

employees to work.

The organization trains the employees on fire safety and other precautions while at work.

66 Cafeteria food is hygienic

67 My organization hires qualified employees with disabilities.

Recreation facilities in the company motivate me to work with employees across the company.

69 My manager engages in ethical practices, which reinforces my integrity.

My organization values and practices integrity and transparency in all its activities.

71 My co-workers engage in ethical practices, which influences my integrity.

72 Opportunities in my company to perform charitable acts are high.

Source: own elaboration.

Based on the 15 expert opinions we received, a few items were modified. Forty items were deleted as there was low consensus on the measurement of the construct and around 25 items were modified. After expert validation, the items were reduced to 72 (Table 2). All the items were measured on a Likert scale measuring from 1 "never" to 5 "always." Statements 4, 5, 6, 11, 13, 19, 20, 25, 31, 35, 36, 40, 41, 42, 43, 45, 46, 47, 48, 55, 59, and 60 were reverse-coded.

\section{Face Validity}

The validity of the tool was established in the process of its preparation. Face validity is the extent to which the content of items is consistent with the construct's definition, based solely on the researcher's judgment (Hair et al., 2011). The items of the tool were listed in tabular form with options to reject, accept or modify each item. Based on the 15 expert opinions, a few items were modified. Sixty-one items were eliminated as there was low consensus on the measurement of the construct and around 25 items were modified. For instance, items like "Employees are trained on disaster management" changed to "Employees are trained on safety measures" and "Employees generally avoid taking food on campus" changed to "Employees generally eat food on campus." After expert validation, the items were reduced to 51. Hence the tool's face validity was established. 


\section{Study Sample}

Employees in service organizations are important because they are central to service; employee attitude and behavior play a vital role in the quality of service. In this regard, employees are primarily responsible for providing a sustainable competitive advantage in the service sector. Therefore, success in the service sector depends on managing and retaining employees (Woods, 1992). Fair treatment and a healthy work environment are things expected by employees who invest their time and energy in an organization. These expectations bring with them an increased concern for employers to focus on perceived fairness by their employees and providing a productive work climate. Hence, the respondents were employees across service sectors.

Judgmental sampling was adopted to select the respondents for the pilot study. The inclusion criteria involved employees across service sectors: healthcare, tourism, education, engineering, communications, transportation, information technology, banking, finance, and management, with more than two years of experience at the current organization. The data was collected from five major cities in India: Delhi and the National Capital Region, Chennai, Mumbai, Kolkata, and Bangalore.

All participants were informed about the purpose and procedure of the study, and they had the right to withdraw at any time during the study. Oral consent to participate in the survey was assumed when the respondent filled the questionnaire. The completion of the questionnaire took approximately 25-30 minutes for each respondent. The confidentiality of data and its future use was communicated. We disseminated 3000 questionnaires across the service sector companies. The investigator finally collected 824 fully filled questionnaires for analysis. The completed scale was collected, and the scores were assigned and systematically pooled for further analysis. The response rate was 27.47 .

Sample size plays an important role in the estimation and interpretation of results in any research. As proposed by Fedell (2003), the minimum sample required for adopting any statistical tool should be greater than or equal to $8 \mathrm{k}+50$, where $\mathrm{k}=$ the number of items involved in the questionnaire and $n$ is the sample size. The number of items in the work environment survey tool was 51 statements. Therefore, solving for $\mathrm{n}, \mathrm{n}=8(51)+50=458$.

The sample for the present study was 824 . The sample size was more than the required minimum to increase the representativeness across the service sector. 
Table 3. Indicating sector-wise breakdown of the sample

\begin{tabular}{|l|c|c|}
\hline \multicolumn{1}{|c|}{ Sector } & No. of respondents & Percentage \% \\
\hline Information Technology & 185 & 22 \\
\hline Banking and Insurance & 149 & 18 \\
\hline ITES (BP0/KP0) & 129 & 16 \\
\hline Hospitals & 87 & 11 \\
\hline Tourism/Airlines & 78 & 9 \\
\hline Telecom & 69 & 8 \\
\hline Retail & 48 & 6 \\
\hline Hotels & 39 & 5 \\
\hline Others Logistics/Consulting/Education/Real Estate & 40 & 5 \\
\hline Total & 824 & 100 \\
\hline
\end{tabular}

Source: own elaboration.

\section{Data Analysis}

Data analysis was performed by using software packages: statistical package for the social sciences (SPSS) version 19 and the analysis of moment structures (AMOS) version 16.

\section{Factor Analysis}

The analysis is an interdependence technique; its purpose is to define the underlying structure among variables. Factor analysis provides tools for analyzing interrelationships (correlations) among a large group of variables that are highly interrelated (Hair et al., 2011). The information contained in several original variables into a smaller set of new composite dimensions (factors) with a minimum loss of information is the objective of factor analysis. There are two ways to understand the latent dimensions, namely principal component analysis and common factor analysis. The dimensions of the work environment services scale (WESS) were explored using the principal component analysis (PCA) and the Varimax rotation.

The main purpose of the principal component analysis was the analysis of data to identify and find patterns to reduce the dimensions of the dataset with a minimal loss 
of information. The Varimax rotation maximizes the sum of variances of squared loadings (squared correlations between variables and factors). This method enhances the interpretability of factors.

For the construction of WESS, I used the Kaiser-Meyer-Olkin measure of sampling adequacy and Bartlett's test as statistical methods to finalize the items to be used in the scale. The KMO measure and Bartlett's test play an important role in accepting sample adequacy. While the KMO measure ranges from 0 to 1 , the world-over accepted index is over 0.6. Moreover, Bartlett's test relates to the significance of the study and thereby shows the validity and suitability of the responses collected to the problem addressed by the study. For factor analysis to be called suitable, Bartlett's test of sphericity must be less than 0.05 .

Table 4. KMO and Bartlett's test of sphericity for sampling adequacy

Kaiser-Meyer-Olkin Measure of Sampling Adequacy .866

Approx. Chi-Square 15178.928

Bartlett's Test of Sphericity Df 406 Sig. .000

Source: own elaboration.

The KMO measure was reported to be high $(.866)$ and Bartlett's test $(\mathrm{p}<.00)$ suggested that principal component analysis (PCA) could be undertaken.

Upon running the factor analysis, factors and commonalities of the work environment services scale were assessed. As an initial process, eigenvalue $>1$ was applied as a guide for extracting components. On examining the table of commonalities of the WESS, all items had values $>0.500$.

The PCA analysis extracted nine factors with a cumulative $68.6 \%$ variance. The explained variance ranged from $11 \%$ to $68.6 \%$. Thus, the extraction of nine factors explained $68.6 \%$ of the variance.

Furthermore, the criteria for retaining the nine factors were eigenvalues greater than one and the ability to describe and label each factor from the items description. The cut-off point of 0.5 for the factor loading was used as the threshold to ensure practical significance. 
Table 5. Details of factors, their loadings, items, and the percentage of variance

\begin{tabular}{|c|c|c|c|c|c|c|c|c|c|}
\hline \multirow{2}{*}{ 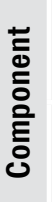 } & \multicolumn{3}{|c|}{ Initial Eigenvalues } & \multicolumn{3}{|c|}{$\begin{array}{l}\text { Extraction Sums of Squared } \\
\text { Loadings }\end{array}$} & \multicolumn{3}{|c|}{$\begin{array}{c}\text { Rotation Sums of Squared } \\
\text { Loadings }\end{array}$} \\
\hline & Total & $\begin{array}{c}\% \text { of } \\
\text { Variance }\end{array}$ & $\begin{array}{c}\text { Cumulative } \\
\%\end{array}$ & Total & $\begin{array}{c}\% \text { of } \\
\text { Variance }\end{array}$ & $\begin{array}{c}\text { Cumulative } \\
\%\end{array}$ & Total & $\begin{array}{c}\% \text { of } \\
\text { Variance }\end{array}$ & $\begin{array}{c}\text { Cumulative } \\
\%\end{array}$ \\
\hline 1 & 8.17 & 28.174 & 28.174 & 8.17 & 28.174 & 28.174 & 3.449 & 11.894 & 11.894 \\
\hline 2 & 2.778 & 9.581 & 37.754 & 2.778 & 9.581 & 37.754 & 3.189 & 10.995 & 22.889 \\
\hline 3 & 1.768 & 6.096 & 43.85 & 1.768 & 6.096 & 43.85 & 2.641 & 9.108 & 31.997 \\
\hline 4 & 1.577 & 5.436 & 49.286 & 1.577 & 5.436 & 49.286 & 2.284 & 7.875 & 39.872 \\
\hline 5 & 1.482 & 5.11 & 54.397 & 1.482 & 5.11 & 54.397 & 2.117 & 7.301 & 47.172 \\
\hline 6 & 1.281 & 4.418 & 58.815 & 1.281 & 4.418 & 58.815 & 1.67 & 5.759 & 52.931 \\
\hline 7 & 1.053 & 3.63 & 62.445 & 1.053 & 3.63 & 62.445 & 1.612 & 5.557 & 58.489 \\
\hline 8 & 0.937 & 3.231 & 65.676 & 0.937 & 3.231 & 65.676 & 1.473 & 5.078 & 63.566 \\
\hline & 0.856 & 2.951 & 68.627 & 0.856 & 2.951 & 68.627 & 1.468 & 5.061 & 68.627 \\
\hline
\end{tabular}

Extraction Method: Principal Component Analysis.

Source: own elaboration.

Table 6. Indicating extracted factor loadings

\section{Factor 1: Ethical Dimension}

In my organization

My manager engages in ethical practices.

.706

My manager's behaviour reinforces my integrity.

My co-workers' engage in ethical practices which influences my integrity.

The grievance handling mechanism is effective.

\section{Factor 2: Autonomy}

Employees can function independent of manager's supervision.

Managers generally do not interfere with the decisions of the employees concerning their work.

Employees here have a great deal of freedom to execute their work.

Employees are provided with a good environment to try out new ideas.

Employees take initiative to get things done. 


\section{Factor 3: Stress and Work Pressure}

* There is always a constant pressure on employees to keep working.

* There is too much of stress because of the work involved.

* There are too many aggressive deadlines to meet.

* There is an imbalance between personal and work life because of work pressures.

* Too much is expected of employees within a short time frame.

\section{Factor 4: Work Practices}

* Management wants to avoid risk in trying out new ideas.

* When employees come in late, they have to compensate by staying late.

* New approaches are discouraged.

\section{Factor 5: Managerial Support}

Immediate managers are sensitive to employee's work/life issues.

Manager's recognize and give credit for the efforts employees put in.

Managers aid employees in planning systematically for their career growth.

There is a lot of investment in resources supporting innovation and research.

\section{Factor 6: Commitment}

Employees speak highly of their job to outsiders.

Employees feel proud to be a part of this organization.

\section{Factor 7: Role Clarity}

* Employees are unclear about what is expected of them.

* Time is wasted because of inefficiencies in processes.

The responsibilities of each employee are clearly defined.

* There is a discrepancy between job description and expectations from supervisors.

\section{Factor 8: Social Responsibility}

Qualified disabled employees are hired.

Opportunities to perform charitable acts are high.

Employees are trained on fire safety and other precautions while at work.

Factor 9: Peer Cohesiveness

Employees take a positive personal interest in colleagues work related issues.

Employees willingly take time off from their busy schedule to help colleagues deal with work-related issues.

(*) indicates reverse coded items

Source: own elaboration. 
Figure 1. Indicating the Measurement model for the confirmation of the work environment dimensions

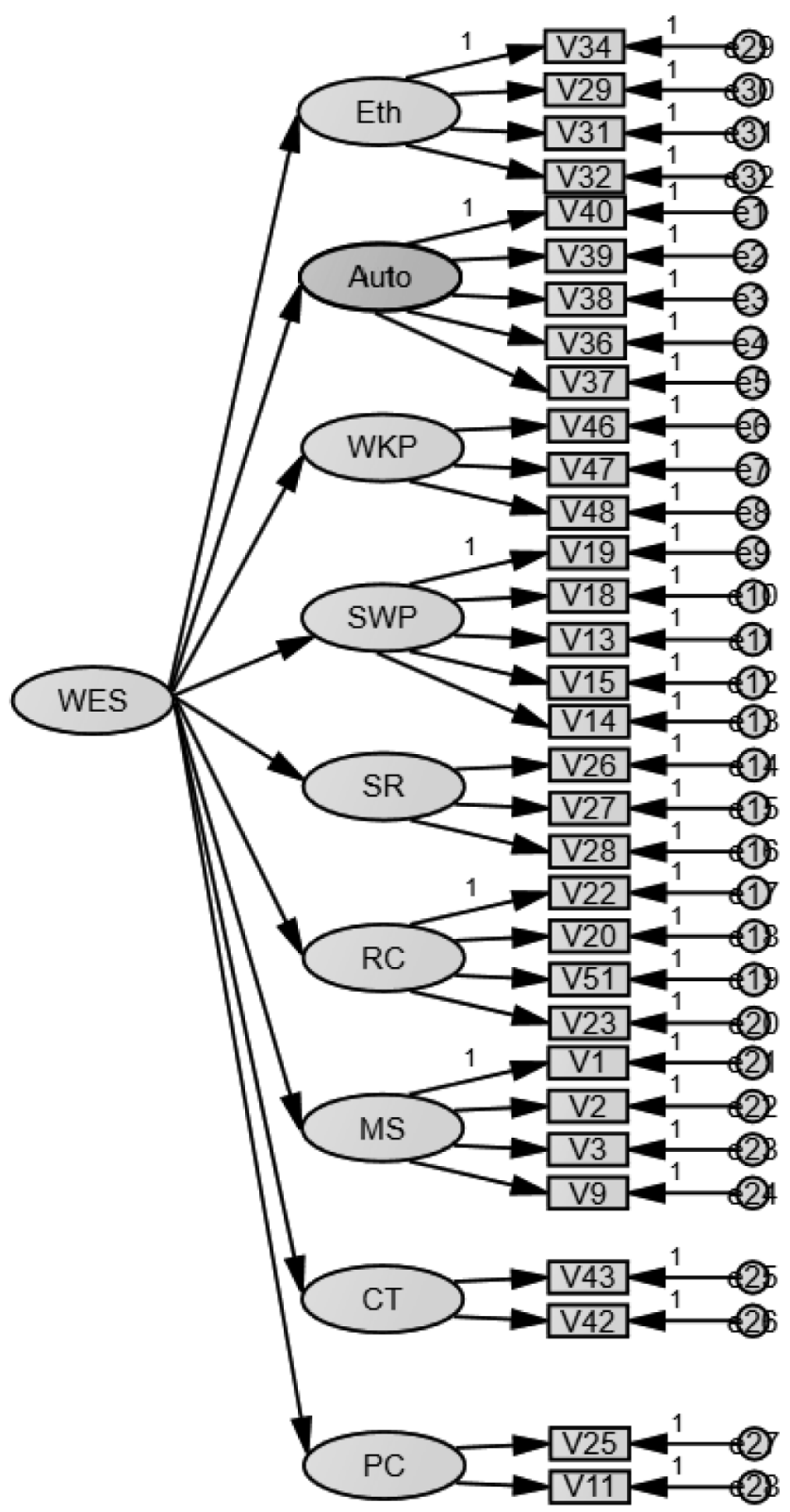

Note: $W E S=$ Work environment scale; Eth=Ethical dimension; Auto=Autonomy; SWP =stress and work pressure; $\mathrm{WKP}=$ work practices; $\mathrm{MS}=$ managerial support; $\mathrm{RC}=$ role clarity; $\mathrm{CT}=$ commitment; $\mathrm{SR}=$ social responsibility; $\mathrm{PC}=$ peer cohesivness

Source: own elaboration. 
Overall, the PCA of WESS revealed a nine-factor structure of 32 items. The WESS appears to be valid and reliable as factorization explained a reasonable percentage of variance and has a high Cronbach's alpha. This indicated that the WESS constructed was robust and further analysis can be done.

The second part of scale development demonstrated confirmatory processes that tested the proposed measurement theory. The measurement theory can be represented with a model that shows how measured variables come together to represent constructs. Confirmatory factor analysis (CFA) enables testing how well do the measured variables represent the construct.

To ensure good construct validity of the WESS - despite the deletion of some items - I examined construct reliability (CR), variance extracted (VE) values, and discriminate validity by comparing the values of average variance extracted (AVE) and squared multiple correlations (SMC) among the nine factors by using structural equation modeling (SEM).

Using the AMOS software, SEM was adopted to confirm the factors manifested in the study. Maximum likelihood estimations are the default options for SEM programs including AMOS.

\section{Construct Validity}

Construct validity is the extent to which a set of measured variables actually represents the theoretical latent construct they are designed to measure (Hair et al., 2006). It is made up of four components: convergent validity, discriminant validity, nomological validity, and face validity. To assess the construct validity of WESS, exploratory and confirmatory factor analytic procedures were applied.

\section{Convergent Validity}

Convergent validity is the extent to which indicators of a specific construct "converge" or share a high proportion of variance in common. Convergent validity identifies the proportion of variance for each factor. To assess this, I examined standardized factor loadings in the measurement model, and I computed CR and AVE.

Construct Reliability $(\mathrm{CR})=\left\{(\text { sum of standardized loadings })^{2}\right\} /\{($ sum of standardized loadings $)^{2}+$ (sum of indicator measurement errors) $\}$. 
Table 7. Average Variance Extracted and Construct Reliability for each construct in the Final Measurement Model

\begin{tabular}{|l|c|c|c|c|}
\hline \multicolumn{1}{|c|}{ Dimensions } & AVE(\%) & \# OF ITEMS & CR (\%) & Coefficient alpha \\
\hline Ethical Dimension & $44 \%$ & 4 & $75 \%$ & .836 \\
\hline Autonomy & $53 \%$ & 5 & $82 \%$ & .861 \\
\hline Stress and Work Pressure & $59 \%$ & 5 & $81 \%$ & .728 \\
\hline Work practices & $50 \%$ & 3 & $60 \%$ & .706 \\
\hline Managerial support & $51 \%$ & 4 & $69 \%$ & .802 \\
\hline Commitment & $51 \%$ & 2 & $52 \%$ & .752 \\
\hline Role Clarity & $43 \%$ & 4 & $57 \%$ & .813 \\
\hline Social responsibility & $60 \%$ & 3 & $73 \%$ & .686 \\
\hline Peer Cohesiveness & $51 \%$ & 2 & $51 \%$ & .650 \\
\hline
\end{tabular}

Source: own elaboration.

As noted by Hair et al. (2006), CR values should be greater than 0.6 while AVE should be above 0.5. I analyzed the convergent validity for the WESS, and so Table 7 shows the values of standardized loading, AVE, CR, and coefficient alpha. The evidence provides initial support for the convergent validity of the nine constructs identified in the WESS. The values support the internal consistency of the data.

\section{Construct Reliability}

Construct reliability is a measure of reliability and internal consistency based on the square of the total of factor loadings for a construct. The CR of the WESS appears in Table 7. The CR estimates of the nine constructs of the WESS exceeded six, which indicated fair construct reliability.

\section{Discriminant Validity}

The discriminant validity examines the extent to which an independent variable is truly distinct from other independent variables in predicting the dependent variable (Hair et al., 2006). It is the extent to which a construct is truly distinct from other constructs. To substantiate the evidence of discriminant validity, the AVE values between dimensions were compared to squared multiple correlations of the two (Hair et al., 2006). If all AVE estimates are larger than the corresponding squared inter-construct 
correlation estimates (SIC) then the construct is said to have discriminant validity (Fornell and Larker, 1981).

Table 8. Indicating inter-construct correlations and squared inter-construct correlation estimates (SIC) Correlations: (Group number 1 - Default model)

\begin{tabular}{|c|c|c|c|c|c|c|c|c|c|c|}
\hline Dimensions & $\begin{array}{l}\text { AVE } \\
(\%)\end{array}$ & 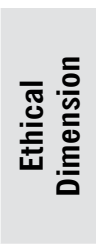 & $\begin{array}{l}\text { 흘 } \\
\text { 를 }\end{array}$ & 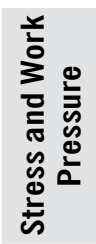 & 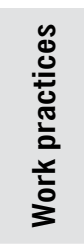 & 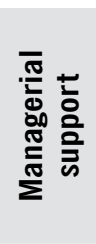 & 志 & $\begin{array}{l}\frac{7}{\frac{T}{\pi}} \\
\frac{\pi}{0} \\
\frac{0}{0} \\
\frac{0}{2}\end{array}$ & 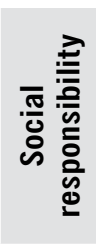 & 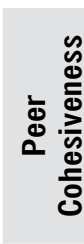 \\
\hline Ethical Dimension & $44 \%$ & - & & & & & & & & \\
\hline Autonomy & $53 \%$ & $49 \%$ & - & & & & & & & \\
\hline $\begin{array}{l}\text { Stress and Work } \\
\text { Pressure }\end{array}$ & $59 \%$ & $0.1 \%$ & $.06 \%$ & - & & & & & & \\
\hline Work practices & $50 \%$ & $17 \%$ & $23 \%$ & $0.3 \%$ & - & & & & & \\
\hline Managerial support & $51 \%$ & $52 \%$ & $54 \%$ & $0.2 \%$ & $25 \%$ & - & & & & \\
\hline Commitment & $51 \%$ & $49 \%$ & $3.8 \%$ & $0.4 \%$ & $14 \%$ & $34 \%$ & - & & & \\
\hline Role Clarity & $43 \%$ & $4 \%$ & $3.8 \%$ & $27 \%$ & $13 \%$ & $.01 \%$ & $.04 \%$ & - & & \\
\hline Social responsibility & $60 \%$ & $38 \%$ & $37 \%$ & $0.7 \%$ & $14 \%$ & $21 \%$ & $30 \%$ & $.01 \%$ & - & \\
\hline Peer Cohesiveness & $51 \%$ & $11 \%$ & $38 \%$ & $0.1 \%$ & $12 \%$ & $8.3 \%$ & $12 \%$ & $.21 \%$ & $3.2 \%$ & - \\
\hline
\end{tabular}

Source: own elaboration.

The discriminant validity for the WESS was established by using the values of the AVE coefficient of correlation and SIC. Table 8 shows the inter-construct correlations and SIC. Out of twenty-one inter-construct correlations, we clearly see that only three SIC values are greater than the AVE. This means the indicators have more in common with the construct they are associated with than they do with other constructs. Therefore, the nine-construct work environment scale demonstrates discriminant validity.

\section{Nomological Validity}

Nomological validity is the extent to which a scale correlates in theoretically predicted ways with other distinct but related constructs. Nomological validity is tested by examining whether the correlations between constructs in a measurement theory make sense. The inter-construct correlations are all positive and significant for the work environment scale, hence nomological validity is confirmed. 
Table 9. Indicating covariance's among the constructs

\begin{tabular}{|c|c|c|c|c|c|c|}
\hline & & & Estimate & S.E. & C.R. & $\mathbf{P}$ \\
\hline ET & $<->$ & $\mathrm{PC}$ & 0.335 & 0.036 & 9.339 & $* * *$ \\
\hline ET & $<->$ & AT & 0.707 & 0.02 & 34.885 & $* * *$ \\
\hline ET & $<->$ & WP & 0.422 & 0.04 & 10.619 & $* * *$ \\
\hline ET & $<->$ & SR & 0.62 & 0.028 & 22.244 & $* * *$ \\
\hline ET & $<->$ & СT & 0.704 & 0.024 & 29.88 & $* * *$ \\
\hline MS & $<->$ & ET & 0.728 & 0.02 & 35.981 & $* * *$ \\
\hline SWP & $<->$ & $\mathrm{RC}$ & 0.529 & 0.03 & 17.587 & $* * *$ \\
\hline PC & $<->$ & AT & 0.195 & 0.036 & 5.454 & $* * *$ \\
\hline$P C$ & $<->$ & WP & 0.173 & 0.043 & 3.994 & $\star * *$ \\
\hline $\mathrm{PC}$ & $<->$ & SR & 0.179 & 0.039 & 4.612 & $* * *$ \\
\hline $\mathrm{PC}$ & $<->$ & CT & 0.357 & 0.037 & 9.603 & $* * *$ \\
\hline MS & $<->$ & $\mathrm{PC}$ & 0.289 & 0.036 & 8 & $* * *$ \\
\hline AT & $<->$ & WP & 0.486 & 0.037 & 12.983 & $* * *$ \\
\hline AT & $<->$ & SR & 0.616 & 0.027 & 22.667 & $\star * *$ \\
\hline AT & $<->$ & СТ & 0.651 & 0.025 & 26.292 & $* * *$ \\
\hline MS & $<->$ & AT & 0.741 & 0.019 & 39.601 & $* * *$ \\
\hline WP & $<->$ & SR & 0.379 & 0.044 & 8.641 & $* * *$ \\
\hline WP & $<->$ & CT & 0.482 & 0.04 & 11.911 & $* * *$ \\
\hline MS & $<->$ & WP & 0.508 & 0.038 & 13.499 & $* * *$ \\
\hline SR & $<->$ & CT & 0.555 & 0.032 & 17.248 & $* * *$ \\
\hline MS & $<->$ & SR & 0.463 & 0.033 & 14.046 & $* * *$ \\
\hline MS & $<->$ & СT & 0.585 & 0.028 & 20.843 & $* * *$ \\
\hline
\end{tabular}

ET - Ethical Dimension; AT - Autonomy; SWP - Stress and Work Pressure; WP - Work practices; MS - Managerial support; CT - Commitment; RC - Role Clarity; SR - Social responsibility; PC - Peer Cohesiveness Source: own elaboration.

As the variables involved in the study satisfy qualitative and quantitative validation, while the measurement model shows adequate fitness to the data, the nine constructs are operationally defined as follows. 


\section{Operational Definitions}

1. Ethical Dimension: The extent to which grievance handling mechanism is effective, while work environment, managers, and co-workers' engage in ethical practices that influence and reinforce integral employee behavior.

2. Autonomy: The extent to which employees experience the freedom to plan and execute work, while the environment encourages creativity, initiative, and self-monitoring in work completion.

3. Stress and Work Pressure: The extent to which the demands in the work environment such as meeting deadlines, expectation management causes pressure on employee work-life balance.

4. Work Practices: The extent to which management discourages new ideas and approaches and reinforces conventional work practices.

5. Managerial Support: The extent to which managers encourage and support employees by being sensitive to their personal and professional needs and by providing infrastructure for growth and innovation.

6. Commitment: The extent to which employees are connected to their job and the organization so that they speak positively about their job and organization.

7. Role Clarity: The extent to which the organization is clear about employee expectations and employees are aware of their duties, responsibilities, and relevant processes, thus increasing efficiency and reducing conflict occurrence.

8. Social Responsibility: The extent to which the work setting exhibits socially responsible behavior such as including a diverse workforce, engaging in charitable acts, and providing opportunities for recreation and leisure.

9. Peer Cohesiveness: The extent of interpersonal interaction in the work environment, such as social communication exchanges and cohesion among workers, along with friendship and support provided by co-workers and cooperative behaviors related to personal and professional life. 


\section{Scoring, Norms, and the Interpretation of WESS}

The percentile scoring is used for developing the norms for WESS.

Table 10. Indicating the norms for interpreting the scores for the nine WESS dimensions

\begin{tabular}{|l|l|l|l|l|}
\hline \multicolumn{1}{|c|}{ Dimensions } & Very Low & Low & Moderate & High \\
\hline Ethical Dimension & Below 2.75 & $2.75-3.5$ & $3.5-4.00$ & Above 4 \\
\hline Autonomy & Below 2.8 & $2.8-3.4$ & $3.4-3.8$ & Above 3.8 \\
\hline Stress and Work Pressure & Below 2.6 & $2.6-3.0$ & $3.0-3.6$ & Above 3.6 \\
\hline Work practices & Below 2.33 & $2.33-3.33$ & $3.33-4.0$ & Above 4.0 \\
\hline Managerial support & Below 2.75 & $2.75-3.5$ & $3.5-4.0$ & Above 4.0 \\
\hline Commitment & Below 3.00 & $3.0-3.5$ & $3.5-4.0$ & Above 4.0 \\
\hline Role Clarity & Below 2.33 & $2.33-3.0$ & $3.0-3.75$ & Above 3.75 \\
\hline Social responsibility & Below 2.66 & $2.66-3.33$ & $3.33-4.0$ & Above 4.0 \\
\hline Peer Cohesiveness & Below 2.95 & $2.95-3.0$ & $3.0-3.5$ & Above 3.5 \\
\hline
\end{tabular}

Source: own elaboration.

Table 11. Indicating the percentiles for each of the dimensions for creating norms or interpretation

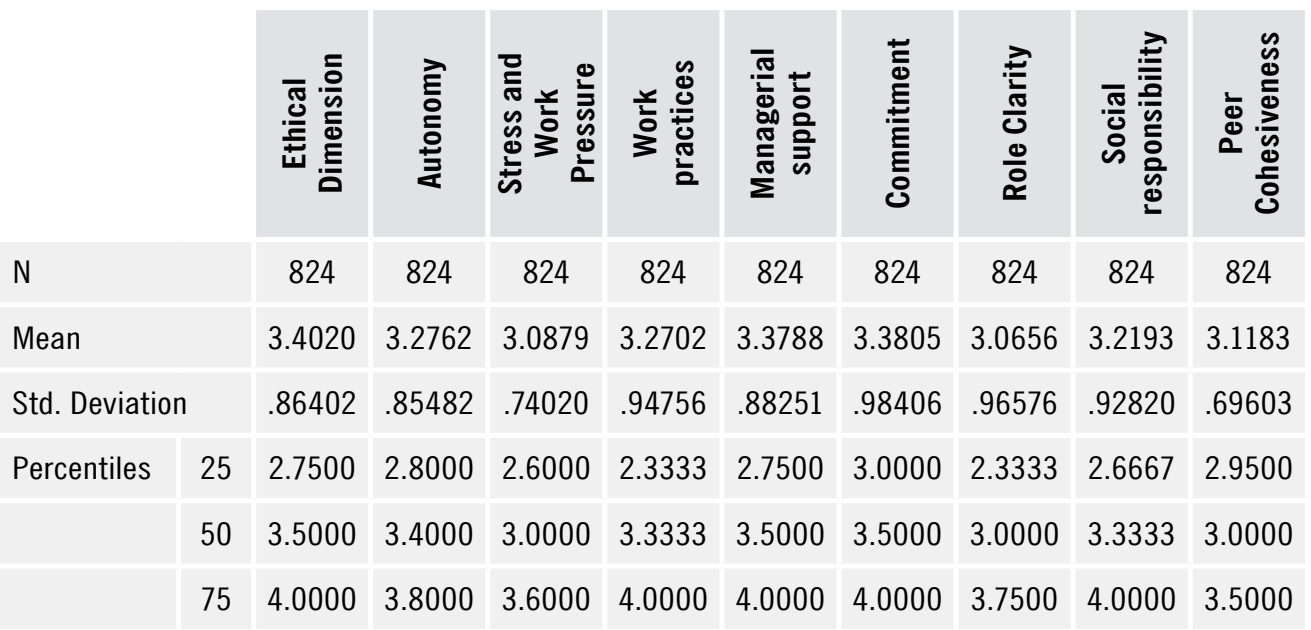

Source: own elaboration. 
1. Ethical Dimension: Any value below the $25^{\text {th }}$ percentile 2.75 for the ethical dimension is considered to be very low. Values between 2.75 and 3.5 are considered to be low. Values between 3.5 and 4 are considered to be moderate and values above 4 are considered to be high from the percentile scoring.

2. Autonomy: Any value below the $25^{\text {th }}$ percentile 2.8 for autonomy is considered to be very low. Values between 2.8 and 3.4 are considered to be low. Values between 3.4 and 3.8 are considered to be moderate and values above 3.8 are considered to be high from the percentile scoring.

3. Stress and Work Pressure: Any value below the $25^{\text {th }}$ percentile 2.6 for stress is considered to be very low. Values between 2.6 and 3 are considered to be low. Values between 3 and 3.6 are considered to be moderate and values above 3.6 are considered to be high from the percentile scoring.

4. Work Practices: Any value below the $25^{\text {th }}$ percentile 2.33 for work practices is considered to be very low. Values between 2.33 and 3.33 are considered to be low. Values between 3.33 and 4.0 are considered to be moderate and values above 4 are considered to be high from the percentile scoring.

5. Managerial Support: Any value below the $25^{\text {th }}$ percentile 2.75 for managerial support is considered to be very low. Values between 2.75 and 3.5 are considered to be low. Values between 3.5 and 4 are considered to be moderate and values above 4 are considered to be high from the percentile scoring.

6. Commitment: Any value below the $25^{\text {th }}$ percentile 3 for commitment is considered to be very low. Values between 3 and 3.5 are considered to be low. Values between 3.5 and 4 are considered to be moderate and values above 4 are considered to be high from the percentile scoring.

7. Role Clarity: Any value below the $25^{\text {th }}$ percentile 2.33 for role clarity is considered to be very low. Values between 2.33 and 3 are considered to be low. Values between 3 and 3.75 are considered to be moderate and values above 3.75 are considered to be high from the percentile scoring.

8. Social Responsibility: Any value below the $25^{\text {th }}$ percentile 2.66 for social responsibility is considered to be very low. Values between 2.66 and 3.33 are considered to be low. Values between 3.33 and 4 are considered to be moderate and values above 4 are considered to be high from the percentile scoring.

9. Peer Cohesion: Any value below the $25^{\text {th }}$ percentile 2.95 for peer cohesion is considered to be very low. Values between 2.95 and 3.00 are considered to be low. Values between 3.00 and 3.5 are considered to be moderate and values above 3.5 are considered to be high from the percentile scoring. 


\section{Conclusion}

Employees are like a fulcrum: they can have a tremendous effect on sales and profitability, both positive and negative. One good employee can draw in a hundred customers. On the flip side, one bad employee can drive away a hundred customers. Competition for good employees is becoming as fierce as it is for good customers. Just as you must market to get new customers, you must also market your organization as a place where great employees want to work. Hiring a good employee is like closing a sale. Similarly, retaining them proves profitable to the company. As the years accrue, there's more stability, knowledge, flexibility, and deeper connection both between the employee and the company and the employee and his or her customers. Moreover, as a team of good employees bonds, turnover reduces because they do want to leave so much. They enjoy the work, camaraderie, and rewards too much to leave for greener pastures. The high growth rate achieved by the Indian economy over the last decade has much to owe to the service sector. Services have contributed around $68.6 \%$ of the overall average growth in the GDP in 2002-2007. For more than a decade now, India's service sector has been the powerhouse of the nation's economic growth and employees in the service sector are its pillars.

The current study has investigated the work environment dimensions such as ethical dimensions, autonomy, stress and work pressure, work practice, commitment, role clarity, social responsiveness, managerial support, and peer cohesion are intangible aspects of the work environment. They are abstract, psychological, or philosophical in nature. Hackman and Oldham (1976) analyze the importance of psychological aspects or needs such as skill variety, task identity, task significance, autonomy, and feedback for improving work environment perception. They suggest that such needs must be addressed if employees are to experience a high perception of work-life balance. In contrast, Taylor (1979) initially suggests that better work environment perception is achieved through basic extrinsic job factors such as pay, working hours, better seating, or a clean environment. However, he later suggests that further aspects can be included such as individual power, employee participation in management, fairness, and equity, social support, the use of one's present skills, self-development, meaningful future at work, the social relevance of work, and effect on extra-work activities. Moreover, Taylor (1979) suggests that factors of work environment vary according to employees, departments, and organizations.

Without a workplace environment open to employee engagement, turnover will increase, and efficiency will decline, leading to low customer loyalty and decreased stakeholder value. Ultimately, because the cost of poor employee engagement will be detrimental 
to organizational success, it is vital for top management to foster positive, effective people managers along with workplace policies and practices that focus on employee well-being, health, and work-life balance. Many people and companies find it difficult to maintain focus on the psychosocial work environment, and much too often, the effort comes to nothing. Companies that are forward-looking can successfully implement improvements whereas other companies slowly come to a halt as they do not measure the work environment. The WESS (Appendix 1) is a tool to be adopted by companies to help them identify areas for interventions and, thus, overcome constraints and difficulties on the road to a better psychosocial work environment.

The above research has some limitations. The data collected for scale development was highly scattered geographically. Most respondents were from Bangalore. The sample suffers from location bias. The sample is not representative of all service sectors, while some service sectors included are not proportionate to the population, therefore reducing the generalization of the scale items. As the scale is not published, the validity and reliability can be a further limiting factor.

The future studies may focus on the new dimensions arising from the new normal and the redefinition of work environment. For validation of this scale, researchers need to study other service sectors, which are not included in this study. The future researchers may use qualitative methods such as in-depth interviews would have added contextual richness to the scale. Studies can adopt this scale and provide the reliability and validity of scale to increase its robustness.

\section{References}

Amabile, T.M., Conti, R., Coon, H., Lazenby, J., and Herron, M. (1996). Assessing the work environment for creativity. Academy of Management Journal, 39(5), 1154-1184. https://doi.org/10.2307/256995.

Aurelio, R. (1996). Motivating a demotivated staff, Management Review, 85(2).

Biswas, S. and Varma, A. (2007). Psychological climate and individual performance in India: test of a mediated model, Employee Relations, 29(6), 664-676.

https://doi.org/10.1108/01425450710826131.

Chan, D.S.K. (2001). Development of an innovative tool to assess hospital learning environments, Nurse Education Today, 21(8), 624-631. https://doi.org/10.1054/nedt.2001.0595.

Fabre, J. (2005). Smart Nursing: How to create a positive work environment that empowers and retains nurses. New York: Springer Publishing Company.

Fletcher, T.D. and Nusbaum, D.N. (2010). Development of the competitive work environment scale: A multidimensional climate construct. Educational and Psychological Measurement, 70(1), 105-112. https://doi.org/10.1177/0013164409344492. 
Fornell, C. and Larker, D.F. (1981). Evaluating structural equation models with unobservable variables and measurement error. Journal of Marketing Research, 18(1), 39-50. https://doi.org/10.1177/002224378101800104.

Gordon, L.V. (1973). Work environment preference schedule \& manual. In: L. Bishop and P.E. Lester (eds.), Instrumentation in education: An anthology. New York: Garland Publishing, Inc.

Hair, J.F., Black, W.C., Babin, B.J., Anderson, R.E., and Tatham, R.L. (2006). Multivariate Data Analysis, 5th Edition. New Dehli: Pearson Education.

Insel, R. and Moos, R.H. (1974). Work Environment Scale. Palo Alto, CA: Consulting Psychologists Press.

Kalliath, T. and Kalliath, P. (2012),"Changing work environments and employee wellbeing: an introduction. International Journal of Manpower, 33(7), 729-737. https://doi.org/10.1108/01437721211268285.

Karasek, R. and Theorell, T. (1990). Healthy work - stress, productivity, and the reconstruction of working life. New York: Basic Books.

Lester, P.E. (ed.) (1993). Instrumentation in Education: An anthology. New York: Garland Publishing, Inc.

Levering, R. (2004). Creating a great place to work: Why it is important and how it is done. Corrections Today, 66(5), 86-88.

Levering, R. and Moskowitz, M. (2004). The 100 best companies to work for. Fortune, 56-76.

Lundgren, D., Ernsth Bravell, M., Börjesson, U. and Kåreholt, I. (2019). The Impact of Leadership and Psychosocial Work Environment on Recipient Satisfaction in Nursing Homes and Home Care. Gerontology and Geriatric Medicine, 5, 1-9. https://doi.org/10.1177/2333721419841245.

Marquez, J. (2007). Creating a culture of safety. Workforce Management, 86(8), 1-4. Available at: http://search.proquest.com/docview/219774646?accountid=38885.

Mayhew, M.J., Grunwald, H.E. and Dey, E.L. (2006). Breaking the silence: Achieving a positive campus climate for diversity from the staff perspective. Research in Higher Education, 47(1), 63-88. https://doi.org/10.1007/s11162-004-8152-z.

Md Asadul Islam, Amer Hamzah Jantan, Yusmani Mohd Yusoff, Choo Wei Chong, Md Shahadat Hossain (2020). Green Human Resource Management (GHRM) Practices and Millennial Employees' Turnover Intentions in Tourism Industry in Malaysia: Moderating Role of Work Environment. Global Business Review, 1-21. https://doi.org/10.1177/0972150920907000.

Ming, V. (2019). Neurotechnologies in the Workplace: Implications of neuroscience at the intersection of technology and work environment. Workforce Solutions Review, 10(4), 8-12. www.ihrim.org.

Newton, C. (2016). What Are Five Theoretical Concepts in the Workplace? http://smallbusiness.chron.com/five-theoretical-concepts-workplace-14115.html.

Ongori, H. (2007). A review of the literature on employee turnover, African Journal of Business Management, 049-054. Available on: http://www.academicjournals.org/ajbm.

Roche, J., Morsi D., and Chandler, G.E. (2009). Testing a work empowerment-work relationship model to explain expertise in experienced acute care nurses. The Journal of Nursing Administration, 39, 115-22. https://doi.org/10.1097/NNA.0b013e31819894dc.

Segall, S.R. (1991). Reflections of your management style. Getting Results for the Hands-on. Manager, 36(2), 1-1.

Shalley, C.E., Gilson, L.L., and Blum, T.C. (2000). Matching creativity requirements and the work environment: Effects on satisfaction and intentions to leave. Academy of Management Journal, 43, 215-223. https://doi.org/10.5465/1556378.

Shumaila Naz, Cai Li, Qasim Ali Nisar, Muhammad Aamir Shafique Khan, Naveed Ahmad, Farooq Anwar (2020). A Study in the Relationship Between Supportive Work Environment and 
Employee Retention: Role of Organizational Commitment and Person-Organization Fit as Mediators. SAGE Open, 10(2), 1-20. https://doi.org/10.1177/2158244020924694.

Smith, J.G., Plover, C.M., McChesney, M.C., and Lake, E.T. (2019). Rural Hospital Nursing Skill Mix and Work Environment Associated With Frequency of Adverse Events. SAGE Open Nursing, 5. 1-13. https://doi.org/10.1177/2377960819848246.

Sonmark, K. and Modin, B. (2017). Psychosocial Work Environment in school and students' somatic health complaints: An analysis of buffering resources. Scandinavian Journal of Public Health, 45(1), 64-72. https://doi.org/10.1177/1403494816677116.

Spector, P.E. and Fox, S. (2003). Reducing Subjectivity in the Assessment of the Job Environment: Development of the Factual Autonomy Scale (FAS). Journal of Organizational Behavior, 24(4), 417-432. https://doi.org/10.1002/job.199.

Staw, B. (ed.) (1998). Research in Organizational Behavior, 1. New York: JAI.

Tae, K.W. and Brower, R. (2018). Job Satisfaction Among Federal Employees: The Role of Employee Interaction With Work Environment. Public Personnel Management, 48(1), 3-26. https://doi.org/10.1177/0091026018782999.

Thorsen, S.V., Huitfeldt Madsen, I.E., Flyvholm, M.A. and Hasle, P. (2017). Associations between the workplace-effort in psychosocial risk management and the employee-rating of the psychosocial Work Environment - a multilevel study of 7565 employees in 1013 workplaces. Scandinavian Journal of Public Health, 45(5), 463-467. https://doi.org/10.1177/1403494817696377.

VanMannen, J. and Schein, E. (1979). Toward a theory of organizational socialization. In: B.M.

Vaishali Dhingra, Rakesh K. Mudgal, Manish Dhingra (2017). Safe and Healthy Work Environment A Study of Artisans of Indian Metalware Handicraft Industry. Management and Labour Studies, 42(2), 152-166. https://doi.org/10.1177/0258042X17714071.

Weinstock, M.P. (1994). Rewarding safety. Occupational Hazards, 56(3), 73-73. Available at: http://search.proquest.com/docview/213692697?accountid=38885.

Zohra Saleem, Zhou Shenbei, Ayaz Muhammad Hanif (2020). Workplace Violence and Employee Engagement: The Mediating Role of Work Environment and Organizational Culture. SAGE Open, 10(2), 1-15. https://doi.org/10.1177/2158244020935885. 


\section{Appendix}

Final Work Environment Services Scale (WESS)

In my organization

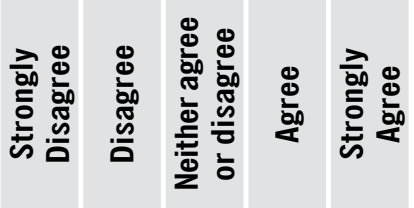

\section{Factor 1: Ethical Dimension}

1. My manager engages in ethical practices.

2. My manager's behaviour reinforces my integrity.

3. My co-workers' engage in ethical practices which influences my integrity.

4. The grievance handling mechanism is effective.

\section{Factor 2: Autonomy}

5. Employees can function independent of manager's supervision.

6. Managers generally do not interfere with the decisions of the employees concerning their work.

7. Employees here have a great deal of freedom to execute their work.

8. Employees are provided with a good environment to try out new ideas.

9. Employees take initiative to get things done.

\section{Factor 3: Stress and Work Pressure}

10. *There is always a constant pressure on the employees to keep working.

11. *There is too much of stress because of the work involved.

12. *There are too many aggressive deadlines to meet.

13. *There is imbalance between personal life and work life because of work pressures.

14. *Too much is expected of employees within a short time frame.

\section{Factor 4: Work Practices}

15. *Management wants to avoid risk in trying out new ideas. 
16. *When employees come in late, they have to compensate by staying late.

17. *New approaches are discouraged.

\section{Factor 5: Managerial Support}

18. Immediate managers are sensitive to employee's work/life issues.

19. Manager's recognize and give credit for the efforts employees put in.

20. Managers aid employees in planning systematically for their career growth.

21. There is a lot of investment in resources supporting innovation and research.

\section{Factor 6: Commitment}

22. Employees speak highly of their job to outsiders.

23. Employees feel proud to be a part of this organization.

\section{Factor 7: Role Clarity}

24. *Employees are unclear about what is expected of them.

25. *Time is wasted because of inefficiencies in processes.

26. The responsibilities of each employee are clearly defined.

27. *There is a discrepancy between job description and expectations from supervisors.

\section{Factor 8: Social Responsibility}

28. Qualified disabled employees are hired.

29. Opportunities to perform charitable acts are high.

30. Employees are trained regarding fire safety and other precautions while at work.

\section{Factor 9: Peer Cohesiveness}

31. Employees take a positive personal interest in colleagues work related issues.

32. Employees willingly take time off from their busy schedule to help colleagues deal with work-related issues.

$\left.{ }^{*}\right)$ indicates reverse coded items

Source: own elaboration. 